\title{
Prevalence and consequences of nutritional depletion in lung transplant candidates
}

\author{
C. Schwebel*,+, I. Pin ${ }^{+}$, D. Barnoud ${ }^{+}$, G. Devouassoux ${ }^{+}$, P.Y. Brichon ${ }^{\#}$, Ph. Chaffanjon ${ }^{\#}$, \\ O. Chavanon", C. Sessa ${ }^{\#}$, D. Blin ${ }^{\#}$, M. Guignier ${ }^{+}$, X. Leverve ${ }^{+}$, Ch. Pison ${ }^{+}$
}

\begin{abstract}
Prevalence and consequences of nutritional depletion in lung transplant candidates. $C$. Schwebel, I. Pin, D. Barnoud, G. Devouassoux, P.Y. Brichon, Ph. Chaffanjon, O. Chavanon, C. Sessa, D. Blin, M. Guignier, X. Leverve, Ch. Pison. (C)ERS Journals Ltd 2000.

ABSTRACT: Nutritional status was studied in lung transplant (LT) candidates. The hypotheses were that nutritional depletion was highly prevalent and lean body mass depletion was a risk factor for a higher mortality both before and after LT.

Of 78 consecutive patients listed for LT, $16(21 \%)$ died while on the waiting list, eight $(10 \%)$ were alive awaiting LT, and $54(69 \%)$ received a graft. Mean age was 42.3 $\pm 4.4($ mean \pm SD). Thirty-eight per cent had a diagnosis of bronchiectasis or cystic fibrosis (BRO/CF), 33\% of emphysema, $20 \%$ of idiopathic pulmonary fibrosis (IPF) and $8 \%$ of primary pulmonary hypertension. Body mass index (BMI) was $20.4 \pm 4.3$ $\mathrm{kg} \cdot \mathrm{m}^{2}$, weight was $87.9 \pm 16.6 \%$ of ideal body weight (IBW).

Patients were classed into four nutritional groups according to IBW and creatinine height index (CHI): I: weight $<90 \%$ IBW and $\mathrm{CHI}<60 \%$ of predicted ( $28 \%$ of cases); II: weight $<90 \%$ IBW and CHI $\geq 60 \%$ (27\%); III: weight $\geq 90 \%$ IBW and CHI $<60 \%$ (17\%); IV: weight $\geq 90 \%$ IBW and $\mathrm{CHI} \geq 60 \%$ (28\%). Overall, $72 \%$ were depleted corresponding to groups I, II and III. Lean body mass depletion occurred despite normal weight in $17 \%$ of the cases (group III). Subjects with BRO/CF were mostly in groups I, II, III whereas IPF were concentrated in group III. Lean body mass depletion was associated with more severe hypoxaemia, reduced 6-minute walking distance and a higher mortality while awaiting. After LT, duration of mechanical ventilation, time spent in intensive care unit (ICU) was related to initial body composition. Survival after LT was lowest in group III.

To conclude, nutritional depletion in lung transplant candidates is highly prevalent and should be more precisely assessed with a special reference to lean body mass since it has specific consequences both while awaiting and after lung transplant. Attempts should be made to increase lean body mass before lung transplant.

Eur Respir J 2000; 16: 1050-1055.
\end{abstract}

\begin{abstract}
*Laboratoire de Bioénergétique Fondamentale et Appliquée, Université Joseph Fourier, Grenoble Cedex, France, ${ }^{+}$Dept de Médecine Aigué Spéciaisée, " Fédération de Chirurgie Cardio-Vasculaire et Thoracique, Hôpital A. Michallon, Centre Hospitalier Universitaire, Université J. Fourier, Grenoble, France.
\end{abstract}

Correspondence: Ch. Pison

Dépt de Médecine Aigué Spéciailisée

Céntre Hospitalier Universitaire de Grenoble

BP217X 38043 Grendole Cedex 9

France

Fax: 33476765617

Keywords: Chronic respiratory failure hypoxaemia

lean body mass

lung transplantation

nutritional depletion

survival

Received: November 291999

Accepted after revision July 182000
Lung transplantation (LT) has become an accepted option for end-stage lung diseases in selected patients with more than 2,500 heart-lung transplantations and 9,000 LT reported in the registry of the International Society for Heart and Lung Transplantation by 1999 [1, 2]. Unfortunately, up to $15 \%$ of candidates die while on the waiting list because of the limited number of organ donors available [1]. Moreover, up to $30 \%$ of the LT recipients die during the first year after LT [1]. Therefore, in order to better use the scarce grafts, it is mandatory to carefully select LT candidates with a predicted optimal outcome [1-3]. In this regard, evaluation of the nutritional status is an integral part of the recipient work-up (all the tests performed before being put on the waiting list). The importance of nutritional depletion while awaiting $[4,5]$ and during the postoperative period $[5,6]$ is controversial. Information on nutrition depletion in LT candidates is rudimentary, relying mostly on body mass index (BMI) [4-7] and often restricted to cystic fibrosis (CF) patients $[4,5]$.

The aim of this study was to report on the prevalence, characteristics and consequences of nutritional depletion in
78 consecutive LT candidates referred to the authors centre and accepted for LT. The hypotheses were that nutritional depletion was highly prevalent in this setting, and that pulmonary function in chronic respiratory failure was related in part to body composition [8]. It was also postulated that lean body mass depletion was a risk factor for higher mortality while awaiting, and after, LT.

\section{Methods}

\section{Study subjects and design}

All the patients referred for LT were selected through a common work-up taking into account general rules for selection of LT candidates and disease-specific guidelines in relation to their underlying end-stage lung diseases [3]. After this selection step, all 78 consecutive patients, placed on the waiting list of the Etablissement Français des Greffes from the authors centre June 1990-June 1998, were entered into this study. Patient characteristics are shown in table 1 . The assessment of nutritional status 
Table 1. - Characteristics of the study population for lung transplantation

\begin{tabular}{lc}
\hline Subjects n & 78 \\
Age yrs & $42.3 \pm 14.4$ \\
Sex male:female & $24(31): 54(69)$ \\
BRO/CF & $30(38)$ \\
EMP & $26(33)$ \\
IPF & $16(20)$ \\
PPH & $6(8)$ \\
FEV1 \% pred & $28.6 \pm 18.4$ \\
FVC \% pred & $45.9 \pm 18.2$ \\
TLC \% pred & $96.5 \pm 35.6$ \\
$P a, O_{2} \mathrm{kPa}$ & $6.95 \pm 1.57$ \\
Pa,CO ${ }_{2} \mathrm{kPa}$ & $6.34 \pm 1.36$ \\
6-min walking distance m & $114 \pm 90$ \\
Body mass index $\mathrm{kg} \cdot \mathrm{m}^{-2}$ & $20.4 \pm 4.3$ \\
Ideal weight \% pred & $87.9 \pm 16.6$ \\
Outcome & \\
Deceased waiting & $16(21)$ \\
Awaiting & $8(10)$ \\
Transplanted & $54(69)$ \\
Procedures performed & \\
HLT & $2(4)$ \\
SLT & $15(27)$ \\
DLT & $37(69)$ \\
\hline
\end{tabular}

Data are presented as mean \pm SD or $\mathrm{n}(\%)$. BRO/CF: bronchiectasis/cystic fibrosis; EMP: emphysema; IPF: idiopathic pulmonary fibrosis; PPH: primary pulmonary hypertension; FEV1: forced expiratory volume in one second; FVC: forced vital capacity; TLC: total lung capacity; $\mathrm{Pa}_{\mathrm{a}} \mathrm{O}_{2}$ : arterial oxygen tension; $P \mathrm{a}, \mathrm{CO}_{2}$ : arterial carbon dioxide tension; HLT: heart-lung transplantation; SLT: single-lung transplantation; DLT: doublelung transplantation.

was performed at the time the patients were listed and was correlated with the functional parameters recorded at assessment. Of the 78 LT candidates, 54 subjects received a lung transplant, 48 survived more than 1 day after the surgical procedure.

\section{Methods}

Patients were categorized into four main diagnostic classes consisting of bronchiectasis/cystic fibrosis (BRO/ $\mathrm{CF}$ ), emphysema (EMP), idiopathic pulmonary fibrosis (IPF), and primary pulmonary hypertension (PPH) accordingly to clinical, functional and specific morphological findings. Lung volumes and air flow parameters were recorded. Arterial blood gases were determined in room air. A 6-min walking test was performed according to the recommendations of GUYATT et al. [9]. Nutritional status was assessed by BMI $\left(\mathrm{kg} \cdot \mathrm{m}^{-2}\right)$. Body weight was expressed as a percentage of ideal weight. Ideal body weight (IBW) was determined as the midpoint of the weight range for a given height and frame size from the 1983 Metropolitan Life Insurance tables [10]. The lean body mass was estimated from the creatinine-height index (CHI). CHI was the ratio of 24-h urinary creatinine excretion of the patient to a reference value based on ideal body weight [11]. The 24-h urinary creatinine excretion was averaged from results of three consecutive days and the mean intra-individual coefficient of variation was $<10 \%$ in the 78 consecutive patients.
Patients were classified according to body composition [8]. Weight $<90 \%$ ideal body weight is an accepted indicator of nutritional depletion. Moreover, a $\mathrm{CHI}<60 \%$ is synonymous with a severe lean body mass depletion [11]. Therefore, IBW $<90 \%$ and $\mathrm{CHI}<60 \%$ were used as cutoff values for stratification (table 2). This resulted in four nutritional groups: group I: weight $<90 \%$ IBW and $\mathrm{CHI}<60 \%$ pred, $\mathrm{n}=22$ ( $28 \%$ of cases); group II: weight $<90 \%$ IBW and $\mathrm{CHI} \geq 60 \%$ of predicted, $\mathrm{n}=21(27 \%)$; group III: weight $\geq 90 \%$ IBW and $\mathrm{CHI}<60 \%$ of predicted, $\mathrm{n}=13(17 \%)$; group IV: weight $\geq 90 \%$ IBW and $\mathrm{CHI} \geq 60 \%$ pred, $\mathrm{n}=22(28 \%)$.

Serum concentration of albumin was determined by radioimmunodiffusion. Fractional skeletal muscle protein breakdown was determined over 3 days by the urinary 3methylhistidine to creatinine ratio after 3 days on a meatfree diet. Normal values are $23 \pm 0.07\left(\mu \mathrm{mol} \cdot \mathrm{mmol}^{-1}\right)$ [12].

Statistical significance was set at $p<0.05$. Results are expressed as mean \pm SD. Analysis of variance was used to compare continuous variables. Survival rates of the 54 consecutive LT patients were estimated using the KaplanMeier product-limit method. The Chi-squared test was used to compare categorical variables such as nutritional groups. For the purpose of analysing the different diagnostic groups within the nutritional groups, the value of Chi-squared of each cell and the distribution of Chisquared with 1 degree of freedom with $p<0.05$ when Chisquared $>3.8$ was used. All analyses were carried out using Statview $\mathbb{R}$ version 4.5 statistical software package (Abacus, Berkeley, CA, USA).

\section{Results}

Characteristics of the 78 consecutive candidates for LT are shown in table 1 . Two-thirds of them were male. The most frequent end-stage lung diseases were the $\mathrm{BRO} / \mathrm{CF}$ with 10 cases of BRO, and 24 of CF. Pulmonary function tests showed severe airway obstruction with chronic hypercapnic respiratory failure in two-thirds of the patients, 52 out of 78 . The 6-min walking test was $109 \pm 90$ meters since six patients were bedridden and unable to perform this test. Fifty-five percent of the patients (groups I, II) had an IBW $<90 \%$ pred and $49 \%$ a BMI $<20$ (table 2 ). Moreover, $72 \%$ of subjects (groups I, II, III) had some form of nutritional depletion with either BM1 $<20$ or lean body mass $<60 \%$ of predicted. According to body composition groups, subjects with $\mathrm{BRO} / \mathrm{CF}$ were mostly in groups I, II, III whereas IPF patients were concentrated in group III, $\mathrm{p}=0.01$ (table 2). EMP and PPH patients were equally distributed in the four groups (table 2). Three diagnostic classes could be identified by $\%$ of IBW: BRO/CF $(0.78 \pm 0.15 \%)$, EMP $(0.90 \pm 0.15 \%)$, and IPF/PPH $(0.98 \pm 0.15 \%$ of IBW), ANOVA, $\mathrm{p}<0.0001$. The serum albumin concentration was $34.8 \pm 6.7 \mathrm{~g} \cdot \mathrm{L}^{-1}$. Serum albumin was not related to the underlying lung disease. Urinary 3-methylhistidine-tocreatinine ratio was within the normal range $(20.1 \pm 4.9$ $\mu \mathrm{mol} \cdot \mathrm{mmol}^{-1}$ ) excluding an active muscle breakdown, whatever the underlying cause of end-stage lung disease.

Anthropometric and functional characteristics according to body composition are shown in table 2 . Groups I and II included younger patients with older patients in groups III and $5 \mathrm{IV}, \mathrm{p}<0.0001$. As expected, lung volumes and 
Table 2. - Anthropometric and functional characteristics according to body composition in 78 consecutive lung transplant candidates

\begin{tabular}{|c|c|c|c|c|c|}
\hline & \multicolumn{4}{|c|}{ Nutritional group } & \multirow{2}{*}{ Chi-squared or ANOVA } \\
\hline & I & II & III & IV & \\
\hline Subjects $n$ & $22(28)$ & $21(27)$ & $13(17)$ & $22(28)$ & NS \\
\hline Sex F:M & $8: 14$ & $6: 15$ & $3: 10$ & $7: 15$ & NS \\
\hline Age yrs & 35.514 .4 & 35.913 .9 & $50.911 .2^{*,+}$ & $50.39 .3^{*,^{+}}$ & $<0.0001$ \\
\hline $\mathrm{BRO} / \mathrm{CF} \%$ & 39 & 36 & 16 & 9 & - \\
\hline EMP \% & 23 & 31 & 4 & 42 & - \\
\hline IPF \% & 19 & 6 & 38 & 38 & - \\
\hline PPH \% & 17 & 17 & 33 & 33 & 0.01 \\
\hline Weight $\%$ ideal & $74.2 \pm 9.9$ & $77.7 \pm 9.8$ & $98.8 \pm 7^{*,+}$ & $105 \pm 11^{*,+}$ & $<0.0001$ \\
\hline $\mathrm{CHI} \%$ pred & $54.6 \pm 8.4$ & $75.8 \pm 8.3^{*}$ & $53.5 \pm 13.1^{+}$ & $84.6 \pm 13.7^{*,+, \#}$ & $<0.0001$ \\
\hline Albumin $\mathrm{g} \cdot \mathrm{L}^{-1}$ & $32.6 \pm 7.3$ & $36.5 \pm 6.2$ & $30.3 \pm 5.4^{+}$ & $36.8 \pm 6.3^{\#}$ & 0.06 \\
\hline$P \mathrm{a}, \mathrm{O}_{2} \mathrm{kPa}$ & $6.19 \pm 1.21$ & $7.81 \pm 1.37^{*}$ & $6.07 \pm 1.13^{+}$ & $7.44 \pm 1.72 *$ & 0.003 \\
\hline 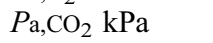 & $6.71 \pm 1.44$ & $6.88 \pm 1.32$ & $5.93 \pm 1.23^{+}$ & $5.91 \pm 1.20^{*,+}$ & 0.04 \\
\hline 6-MWD m & $52 \pm 48$ & $178 \pm 85^{*}$ & $88 \pm 80^{+}$ & $140 \pm 86^{*, \#}$ & $<0.0001$ \\
\hline
\end{tabular}

Data are presented as mean \pm SD or $\mathrm{n}(\%)$. F: female; M: male; BRO/CF: bronchiectasis/cystic fibrosis; EMP: emphysema; IPF: idiopathic pulmonary fibrosis; PPH: primary pulmonary hypertension; CHI: creatinine height index; \% pred: per cent of predicted; $6-$ MWD: 6-min walking distance. *: corresponds to significant difference compared to Group I with the post-hoc test of Fisher; ${ }^{+}$: significant difference compared to Group II; ${ }^{\#}$ : significant difference compared to Group III. Nutritional group: I: weight $<90 \%$ ideal, $\mathrm{CHI}<60 \%$ pred; II: weight $<90 \%$ ideal, CHI $60 \%$ pred; III: weight $\geq 90 \%$ ideal, CHI $<60 \%$ pred; IV: weight $\geq 90 \%$ ideal, $\mathrm{CHI} \geq 60 \%$ pred; ns: not significant.

spirometry were related to the underlying diseases. Patients from groups I and II exhibited hypercapnic respiratory failure compared to patients in group III and IV. Serum albumin was lower in groups I and III. When considering groups I and III as opposed to groups II and $\mathrm{IV}$, lean body mass depletion was significantly associated with more severe hypoxaemia $(\mathrm{p}=0.003)$ and a lower 6min walking distance $(\mathrm{p}<0.0001)$.

Sixteen patients $(21 \%)$ died while awaiting LT. Since graft allocation is by chance, the factors associated with death during the waiting time were examined. The average time between inscription on the waiting list and transplantation (54 cases) or death (16 cases) was similar: $153 \pm$ 129 versus $118 \pm 139$ days, $\mathrm{p}=0.37$. IBW was unable to predict death while waiting LT $(\mathrm{p}=0.44)$, and neither could body mass $(\mathrm{p}=0.11)$. The occurrence of a lean body mass $<60 \%$ of predicted was strongly associated with a higher mortality: $31.4 \%$ died in the low lean body mass group versus $11.6 \%$ in the nondepleted group, $\mathrm{p}=0.03$ while awaiting.

After LT, six patients out of 54 survived $<1$ day due to uncontrolled bleeding in four cases, primary graft failure in one case, and septic shock in one case. Nutritional status was shown to play a role in the early postoperative course of the 48 consecutive LT patients who survived $>1$ day as shown in table 3. Post LT, the four main diagnoses were not different within the four nutritional subgroups. The length of mechanical ventilation $(p=0.05)$ and the time spent in ICU $(p=0.0002)$ were related to initial body composition. In this regard, group III did the worst and survival was the poorest as compared to groups I, II, IV, $\mathrm{p}=0.009$ (fig. 1a). The mean follow-up after LT/was 23 months (0-67). Of 54 lung recipients 33 died during this period, six within $24 \mathrm{~h}$ after the procedure, 12 within 6 months and 15 after 6 months. Early deaths were mostly related to infections, whereas late deaths were due to bronchiolitis obliterans syndrome. Survival of the 54 lung recipients was $40 \%$ at 5 yrs.
The influences of body composition and lean body mass depletion on survival of the 54 consecutive LT recipients are shown in figures $1 \mathrm{a}$ and $1 \mathrm{~b}$. Although differences in survival did not reach statistical significance, there was a trend towards a higher mortality in groups I and III as opposed to groups II and IV.

\section{Discussion}

The main finding of this study is a high prevalence of nutritional depletion in LT candidates with clinically relevant consequences. In this setting, of very severe chronic respiratory failure, lean body mass depletion does not always parallel decreased body weight as shown by the group III patients. Depletion of lean body mass is related to a greater extent to the degree of hypoxaemia, to the 6-min walking distance and to the outcome while awaiting and after LT than to body weight.

In chronic obstructive pulmonary disease (COPD), nutritional depletion is common and the reported prevalence of IBW $<90 \%$ is $35 \%$, and $25 \%$ of cases have BMI $<20 \mathrm{~kg} \cdot \mathrm{m}^{-2}[8,13,14]$. The figures are much higher than that since $54 \%$ of the LT candidates had an IBW $<90 \%$ and $49 \%$ had a BMI $<20$. The use of two criteria, weight $<90 \%$ of IBW and/or a $\mathrm{CHI}<60 \%$ pred shows that $72 \%$ of the patients were severely depleted. Several points may account for these discrepancies in the prevalence of nutritional depletion: 1) the method of nutritional assessment, 2) the underlying pulmonary disease and the severity of the disease, 3) the degree of hypoxaemia and 4) the level of systemic inflammation. It has been shown by ScHols et al. [8] that assessment of the fat-free mass by bioelectrical impedance or by $\mathrm{CHI}$ is more sensitive in detecting nutritional depletion than body weight alone. In that study, $9.4 \%$ of the patients with COPD exhibited a depletion of their fat-free mass despite a normal weight [8]. The authors of the present study confirmed this subtype of depletion in $17 \%$ of the patients (group III) 
Table 3. - Consequences of body composition on the postoperative course in 48 consecutive lung transplant patients who survived $>1$ day

\begin{tabular}{lccccc}
\hline & \multicolumn{4}{c}{ Nutritional group } & \multirow{2}{*}{ Chi-squared or ANOVA } \\
\cline { 2 - 5 } & I & II & III & IV & NS \\
\hline Subjects n & $14(32)$ & $11(25)$ & $5(11)$ & $18(32)$ & NS \\
Sex F:M & $4: 10$ & $2: 9$ & $0: 5$ & $7: 11$ & 0.002 \\
Age yrs & $36.2 \pm 14.9$ & $38.5 \pm 14.6$ & $57.6 \pm 3.3^{*,+}$ & $49.2 \pm 9.4^{*,+}$ & \\
BRO/CF \% & 41 & 28 & 12 & 50 & 0.18 \\
EMP \% & 17 & 0 & 6 & 50 & 0.05 \\
IPF \% & 30 & 0 & 0 & $2.5(4-29)^{\#}$ & \\
PPH \% & 33 & $1(0.8-28)$ & $17(1.4-88)^{*,+}$ & $16(12-30)^{\#}$ & 0.0002 \\
MV days & $5.5(7-34)$ & $17(8-35)$ & $53(18-89)^{*,+}$ & \\
ICU, days & $17(7-72)$ & &
\end{tabular}

Data are presented as mean $\pm \mathrm{SD}, \mathrm{n}(\%)$ or median (range) unless otherwise stated. F: female; M: male; BRO/CF: bronchiectasis/cystic fibrosis; EMP: emphysema; IPF: idiopathic pulmonary fibrosis; PPH: primary pulmonary hypertension; MV: mechanical ventilation; ICU: in intensive care unit; *: significant difference compared to Group I with the post-hoc test of Fisher; ${ }^{+}$: significant difference compared to Group II; ${ }^{\#}$ : significant difference compared to Group III; NS: not significant. For nutritional groups see table 2.

where lean body mass depletion was probably masked by relatively abundant fat and cor pulmonale. Finally, among patients with lean body mass depletion, $23 \%$ (i.e. 13 of group III out of 56 of groups I, II, III) had a normal weight leading to an erroneous evaluation of the actual nutritional status (table 2). In contrast, among patients with a

a)

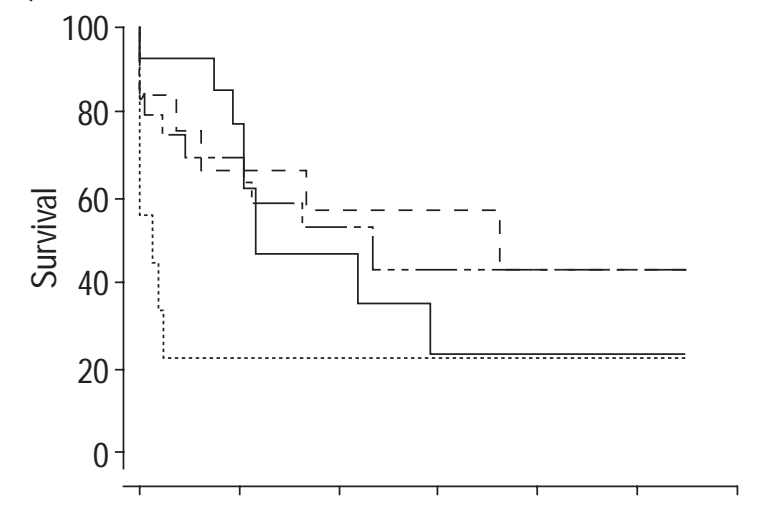

b)

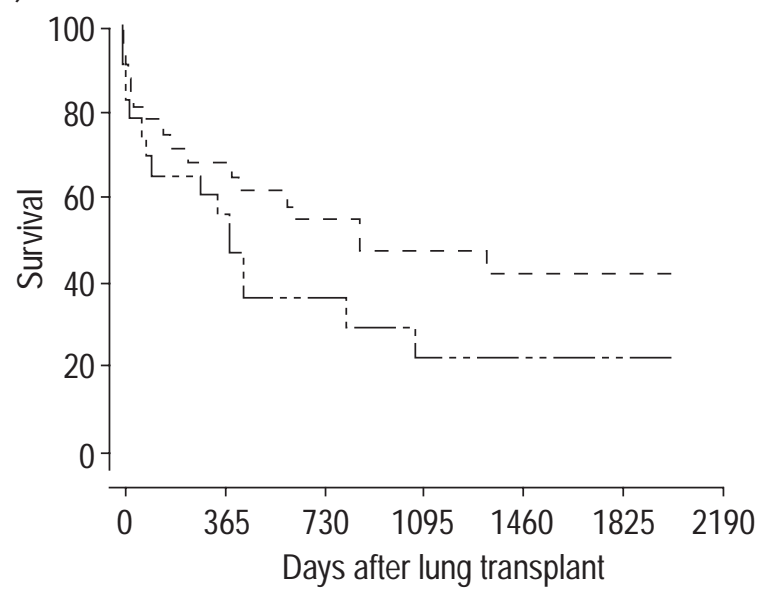

Fig. 1. - Survival according to a) body composition, Group I, II, III and $\mathrm{IV}$, and creatinine height index (CHI) $<60 \%(\mathrm{p}=0.009)$ or $\mathrm{b}) \geq 60 \%$ of predicted in 54 consecutive lung transplant recipients $(\mathrm{p}=0.12)$. a) - : Group I, n=14; - - - : Group II, n=12; ….... Group III, n=9; - - - : Group IV, $n=19$; b) - - - C CHI <60\% pred, $n=23 ;----$ : CHI $>60 \%$ pred, $\mathrm{n}=31$. normal body weight (groups III, IV), 37\% exhibited a profound lean body mass depletion (group III).

The underlying pulmonary disease and the stage of the disease is associated with different risks of cachexia. In the study by Chailleux et al. [15] where 26,140 patients were followed for $10 \mathrm{yrs}$, the prevalence of nutritional depletion differed largely in relation to the aetiology of chronic respiratory failure. For example, prevalence of undernutrition defined by a body weight $<90 \%$ of IBW was $43 \%$ in patients with bronchiectasis, $65 \%$ in emphysema, $33 \%$ in chronic bronchitis, and $28 \%$ in IPF patients. In IPF and PPH LT candidates, body weight is well maintained as already shown by the Toronto group [7]. In the cases of IPF concentrated in group III, lean body mass depletion seems to be masked by a relative abundant fatmass perhaps related to the use of corticosteroids. In CF patients listed for LT, nutritional depletion is common with a mean weight of $\sim 80 \%$ of IBW and a BMI of 18 $\mathrm{kg} \cdot \mathrm{m}^{-2}[4,5,7,13]$. In COPD patients, the prevalence of nutritional depletion increases with the degree of bronchial obstruction $[8,10,14,16,17]$, the level of hypoxaemia $[8,15]$ and the subtype of COPD, emphysema patients being more depleted [14]. Hypoxaemia per se modifies muscle mass through a sharp decline in protein synthesis so that oxygen supply can adapt to demand [18]. Hypoxaemia may also act through a release of pro-inflammatory cytokines [19]. An important factor related to nutritional depletion is the level of systemic inflammation $[20,21]$. The high prevalence of undernutrition in the patients was mostly related to the high proportion with severe chronic infection $(\mathrm{BRO} / \mathrm{CF})$ responsible for a chronic inflammatory state associated with profound hypoxaemia. To further understand the mechanisms of lean body mass depletion, the authors looked for evidence of muscle breakdown. In this regard the urinary 3-methylhistidine creatinine ratios were within the normal range excluding an increase in proteolysis and favouring the hypothesis of a decrease in protein synthesis $[18,22]$. This pattern of adaptation to chronic hypoxaemia is unique and differs from responses to injury $[22,23]$.

Classically, the risk of death while waiting LT depends on the underlying end-stage disease and its severity, the risk being lower in emphysema patients as compared to 
CFBRO, PPH or IPF patients. In the authors experience, the most sensitive predictor of death while a waiting LT is the depletion of lean body mass $<60 \%$ pred, regardless of the nature of the end-stage lung disease. This is in accordance with the finding that a BMI $<18$ was a risk factor for death while. awaiting LT in a series of $62 \mathrm{CF}$ patients [4]. Accordingly, weight was a highly significant parameter in univariate analysis of survival while awaiting LT in 67 consecutive patients listed for GF [5]. In the CF population, attempts to increase weight have a positive impact on survival [24]. In end-stage lung diseases, lean body mass seems to be a better tool to assess nutritional depletion and monitoring this parameter in lung transplant candidates is recommended. If mortality is considered, the study confirms that nutritional status per se is of value to predict survival while awaiting LT [4, $5,13,16,17]$.

In the postoperative course, nutritional depletion increases the risk of death, mainly in CF patients, as shown by different groups [5, 6,13$]$ but not by others [4]. Undernutrition may act indirectly through an increased risk of infection. In a series of 4,515 heart transplant recipients, an IBW $<80 \%$ was a clear risk factor for increased mortality after transplantation due to a greater risk of infections [25]. In the present series, there was a trend towards a higher postoperative mortality in groups I and III as compared to group II and IV. Group III was the worst with a significantly higher mortality as compared to groups I, II, and IV as a whole. Postoperative mortality was not correlated with diagnostic classes, but the risk of type II statistical error should be highlighted. However, early deaths were related to infections and the relation to lean body mass depletion is well established.

Poor nutritional status and particularly low lean body mass had a significant impact on the length of postoperative mechanical ventilation and ICU stay even though it did not seem to increase early mortality. Since a low muscle mass doubles the duration of stay in ICU, the costs dramatically increase, thus justifying efforts to increase weight through pulmonary rehabilitation and renutrition. This strategy may be life saving and cost-effective. The role of anabolic intervention deserves further attention since one report showed promising effects in a LT candidate [26] as opposed to the absence of significant improvement in outpatient COPD or during weaning from the ventilator [27-29]. In the postoperative course, omega-3 fatty acid supplements may be of value with respect to the special risk of infection in these patients [30].

To conclude, nutritional status in lung transplant candidates should be more precisely assessed with special reference to lean body mass since it has specific consequences both while awaiting and after lung transplantation. Creatinine height index is a useful and inexpensive marker of this. An alternative is represented by bioelectrical impedance to assess fat-free mass. Severe nutritional depletion is not, to the authors' minds, a contraindication to lung transplantation but mortality is higher before and after it. Attempts should be made to increase lean body mass before lung transplantation.

Acknowledgements. The authors would like to thank J. Quentin-Ferran for collection of the data and D. Veale, for correction of the English text.

\section{References}

1. Trulock EP. Lung transplantation. Am J Respir Crit Care Med 1997; 155: 789-818.

2. Hosenpud JD, Bennett LE, Keck BM, Fiol B, Boucek MM, Novic RJ. The registry of the International Society for Heart and Lung Transplantation: sixteenth official report. J Heart Lung Transplant 1999; 18: 611-626.

3. Maurer JR, Frost AE, Estenne M, Higenbottam T, Glanville AR. International guidelines for the selection of lung transplant candidates. $J$ Heart Lung Transplant 1998; 17: 703-709.

4. Snell GI, Bennetts K, Bartolo J, et al. Body mass index as a predictor of survival in adults with cystic fibrosis referred for lung transplantation. J Heart Lung Transplant 1998; 17: 1097-1103.

5. Sharples L, Hamaway T, Dennis C, Caine N, Higenbottam T, Wallwork J. Prognosis of patients with cystic fibrosis awaiting heart and lung transplantation. $J$ Heart Lung Transplant 1996; 12: 669-674.

6. Plöchl W, Pezawas L, Artemiou O, Grimm M, Klepetko W, Hiesmayr M. Nutritional status, ICU duration and ICU mortality in lung transplant recipients. Intensive Care Med 1996; 22: 1179-1185.

7. Madill J, Maurer JR, de Hoyos A. A comparison of preoperative and postoperative nutritional states of lung transplant recipients. Transplantation 1993; 56: 347-350.

8. Schols AMWJ, Soeters PB, Dingemans AMC, Mostert R, Frantzen PJ, Wouters EFM. Prevalence and characteristics of nutritional depletion in patients with stable COPD eligible for pulmonary rehabilitation. Am Rev Respir Dis 1993; 56: 347-350.

9. Guyatt GH, Pugsley SO, Sullivan MJ, et al. Effect of encouragement on walking test performance. Thorax 1984; 39: 818-822.

10. Metropolitan Life Insurance Company. New weight standards for men and women. Stat Bull Metrop Life Found 1983; 64: 1-4.

11. Blackburn GL, Bistrian BR, Maini BS, Schlamm HT, Smith MF. Nutritional and metabolic assessment of the hospitalized patient. J Parenter Enteral Nutr 1977; 1: 1122.

12. Sjölin J, Stjernström H, Henneberg S, Hambraeus L, Friman G. Evaluation of urinary 3-methylhistidine excretion in infection by measurements of 3-methylhistidine and the creatinine ratios. Am J Clin Nutr 1989; 49: 62-70.

13. Dennis C, Caine N, Sharples L, et al. Heart-lung transplantation for end-stage respiratory disease in patients with cystic fibrosis at Papworth hospital. J Heart Lung Transplant 1993; 12: 893-902.

14. Engelen MPKJ, Schols AMWJ, Baken WC, Wesseling GJ, Wouters EFM. Nutritional depletion in relation to respiratory and peripheral skeletal muscle function in outpatients with COPD. Eur Respir J 1994; 7: 1793-1797.

15. Chailleux E, Fauroux B, Binet F, Dautzenberg B, Polu JM. Predictors of survival in patients receiving domiciliary oxygen therapy or mechanical ventilation. A 10year analysis of ANTADIR observatory. Chest 1996; 109: 741-749.

16. Landbo C, Prescott E, Lange P, Vestbo J, Almdal TP. Prognostic value of nutritional status in chronic obstructive pulmonary disease. Am J Respir Crit Care Med 1999; 160: 1856-1861.

17. Gray-Donald K, Gibbons L, Shapiro SH, Macklem PT, Martin JG. Nutritional status and mortality in chronic obstructive pulmonary disease. Am J Respir Crit Care Med 1996; 153: 961-966. 
18. Bunn HF, Poyton RO. Oxygen sensing and molecular adaptation to hypoxia. Physiol Rev 1996; 76: 839-885.

19. Hempel SL, Monick MM, Hunninghake GW. Effect of hypoxia on release of IL1 and TNF by human alveolar macrophages. Am J Respir Cell Mol Biol 1996; 14: 170176.

20. Elborn JS, Cordon SM, Western PJ, Macdonald IA, Shale DJ. Tumor necrosis factor-alpha, resting energy expenditure and cachexia in cystic fibrosis. Clini Sci 1993; 85: 563-568.

21. Schols AMWJ, Buurman WA, Staal-van den Brekel AJ, Dentener MA, Wouters EFM. Evidence for a relation between metabolic derangements and increased levels of inflammatory mediators in a subgroup of patients with chronic obstructive pulmonary disease. Thorax 1996; 51: 819-824.

22. Morrison WL, Gibson JNA, Scrimegeour C, Rennie MJ. Muscle wasting in emphysema. Clin Sci 1988; 75: 415420.

23. Weissman C. The metabolic response to stress: an overview and update. Anesthesiology 1990; 73: 308-327.

24. Corey M, McLaughlin FJ, Williams M, Levison H. A comparison of survival, growth and pulmonary function in patients with cystic fibrosis in Boston and Toronto. $J$ Clin Epidemiol 1988; 41: 583-591.
25. Grady KL, White-Williams C, Naftel D, et al. J Heart Lung Transplant 1999; 18: 750-763.

26. Pichard C, Kyle U, Jolliet P, et al. Treatment of cachexia with recombinant growth hormone in a patient before lung transplantation: a case report. Crit Care Med 1999; 27: 1639-1642.

27. Burdet L, De Muralt B, Schutz Y, Pichard C, Fitting JW. Administration of growth hormone to under-weight patients with chronic obstructive pulmonary disease patients: a prospective randomized controlled study. $\mathrm{Am}$ J Respir Crit Care Med 1997; 156: 1800-1806.

28. Schols AMWJ, Soeters PB, Mostert R, Pluymers RJ, Wouters EFM. Physiological effects of nutritional support and anabolic steroids in COPD patients. A placebo controlled randomized trial. Am J Respir Crit Care Med 1995; 152: 1268-1274.

29. Pichard C, Kyle U, Chevrolet JC, et al. Lack of effects of recombinant growth hormone on muscle function in patients requiring prolonged mechanical ventilation: a prospective randomized controlled study. Crit Care Med 1996; 24: 403-413.

30. Galban C, Montejo JC, Mesejo A, et al. An immuneenhancing enteral diet reduces mortality rate and episodes of bacteremia in septic intensive care unit patients. Crit Care Med 2000; 28: 643-648. 